\title{
Volatile organic compounds (VOCs) from Bacillus subtilis CF-3 reduce anthracnose and elicit active defense responses in harvested litchi fruits
}

Pengyu Zhao ${ }^{1,2 \dagger}$, Peizhong $\mathrm{Li}^{1 \dagger}$, Shiyuan $\mathrm{Wu}^{1}$, Minshun Zhou ${ }^{1}$, Ruicong Zhi ${ }^{* *}$ and Haiyan Gao ${ }^{1 *}$ (D)

\begin{abstract}
In this study, we investigated the effects of volatile organic compounds (VOCs) produced by Bacillus subtilis CF-3 on the growth and development of Colletotrichum gloeosporioides and evaluated the elicitation of active defense responses in harvested litchi fruits. In vitro experiments were conducted to explore the bacteriostatic effect of VOCs in inhibiting pathogenic fungi by means of plate enthalpy test, scanning electron microscopy, transmission electron microscopy, and gas chromatography-mass spectrometry (GC-MS). The results showed that 2,4-di-tert-butylphenol and CF-3 24-h fermentation broth (24hFB) can significantly inhibit the germination of fungal spores, disrupt hyphal and cell morphology, and decrease cell membrane fluidity and integrity, resulting in the changes of indexes. In addition, the bacteriostasis of VOCs in the defensive ability of litchi fruits to C. gloeosporioides was studied, and it was shown that 2,4-di-tert-butylphenol and CF-3 24hFB can inhibit the activity of the pathogenic enzymes (pectinase and cellulase) secreted by C. gloeosporioides to reduce the decomposition of plant tissues, activate antioxidant enzymes (peroxidase, polyphenol oxidase, catalase, and superoxide dismutase) in the fruit to eliminate excessive reactive oxygen species in fruits in order to reduce plant cell damage and activate disease resistance enzymes (phenylalanineammonialyase, chitinases, $\beta$-1,3-glucanase) to enhance the resistance of litchi fruits to C. gloeosporioides and inhibit its growth. This study investigated the bacteriostasis of VOCs in inhibiting C. gloeosporioides and inducing the resistance of litchi fruits, providing a theoretical basis for future applications.
\end{abstract}

Keywords: B. subtilis CF-3 VOCs, C. gloeosporioides, Antibacterial effect, Litchi fruit

\section{Introduction}

Litchi anthracnose is a common disease of litchi that mainly affects young leaves, flower spikes, and mature or close to mature fruits, resulting in rotten flower and fruit (Liu 2006). For a long time, one or a combination of several methods, such as refrigerated atmosphere storage, chemical agents, physical treatment, etc., have been

\footnotetext{
*Correspondence: zhirc@ustb.edu.cn; hygao1111@126.com

†Pengyu Zhao and Peizhong Li contributed equally to this work and should be considered co-first authors

'School of Life Sciences, Shanghai University, Shanghai 200444, People's Republic of China

${ }^{2}$ School of Computer and Communication Engineering, University of Science and Technology Beijing, Beijing 100083, People's Republic of China
}

used to keep litchi fresh and disease-free after harvesting (Wang et al. 2001). In addition to antioxidants and food additives, the main components of litchi antiseptic preservatives are chemical fungicides, including organic and inorganic compounds, such as prochloraz, sorbate, $\mathrm{NiCl}_{2}$, etc., which have different degrees of toxicity and residual after use (Qi et al. 2015). Therefore, it is particularly important to seek safe, nontoxic, and efficient technology for controlling litchi post-harvest decay to promote the healthy development of litchi industry. Therefore, the current hotspot of biological control, as well as the efficient and safe solution for litchi fruit decay, is to screen beneficial microorganisms with antagonistic action and to extract relevant antibacterial chemicals to inhibit or 
kill pathogenic microorganisms in order to prolong the storage period and improve fruit preservation.

In recent years, the antibacterial effect of $B$. subtilis has been a research topic of interest worldwide. $B$. subtilis is a mesophilic aerobic or facultative anaerobic gram-positive rod-shaped bacterium (Sonenshein and Losick 1994). It is widely distributed in nature, nontoxic and harmless to humans, easy to isolate and cultivate, and has broad-spectrum antibacterial activity. The $B$. subtilis vegetative cells are affected by changes in external environmental factors, such as nutrient deficiencies, accumulation of metabolites, temperature changes, etc. Endospores, which are highly resistant to radiation, heat drying, extreme pressure, hydrostatic pressure, and some toxic chemicals (Nicholson et al. 2000; Setlow 2010), are formed intracellularly and have strong anti-reverse ability to produce antibiotics and enzymes, peptides, lipopeptides, polyenes, amino acids, etc., (Ahimou and Deleu 1999). Waewthongrak et al. (2015) showed that the cyclolipopeptides secreted by the B. subtilis strain ABSS14 elicit a broad-spectrum antibiotic effect, reducing the number of Penicillium strains exposed to B. subtilis and cell-free cultivation by $96.2 \%$ and $90.9 \%$, respectively. Ambrico and Trupo (2017) further confirmed that Iturin A produced by $B$. subtilis ET-1 can effectively inhibit the occurrence of blue mold on lemon fruit and gray mold on strawberry fruit. Ahmad et al. (2017) isolated and identified a B. subtilis strain 330-2 from rapeseed; this strain was found to secrete indole-3-acetic acid, iron carrier, lysozyme, organic and inorganic phosphates from different sources, and zinc ions. It was reported to effectively inhibit the growth of Rhizoctonia solani AG1-IA, Fusarium oxysporum, Alternaria tenuis Nees, Cochliobolus heterostrophus, and Nigrospora oryzae.

In the study of VOCs in B. subtilis, (Vespermann et al. 2007) reported the VOCs produced by seven strains of $B$. subtilis B2 against a phytopathogen by measuring the VOCs of nine different bacterial strains against the mycelial growth inhibition of Rhizoctonia solani. Leelasuphakul et al. (2008) isolated 205 strains of Bacillus from soil and selected 23 strains of $B$. subtilis. It was found that the VOCs produced by them could inhibit the growth of Penicillium digitatum by approximately $30-70 \%$. Li et al. (2015) found that B. subtilis XF-1 and 168 can effectively inhibit the growth of Fusarium solani, and the main VOCs detected by solid-phase microextraction gas chromatography-mass spectrometry (SPME-GC-MS) included 2-methylbutanone, 2-pentanone, 3-methyl2-pentanone, 2,5-dimethylpyrazine, benzaldehyde, and 5-methyl-2-heptanone. It can be seen that $B$. subtilis produces a variety of VOCs, with different VOCs having different antibacterial activities against different pathogenic bacteria. The VOCs of $B$. subtilis are composed of a variety of chemical substances, which have strong antibacterial effects and can inhibit the growth of different kinds of pathogens. However, B. subtilis has not been widely used in actual preservation technology because the functional effects of the main components are lack of scientific basis and volatile matter separation technology. The mechanism of the antibacterial action of related volatile substances is not proven. Therefore, the future studies should identify and explore VOCs and elucidate the mechanism of their bacteriostatic action.

Compared with non-volatile antibacterial substances, VOCs exist in the form of gas and are more easily adsorbed by plants in the form of chemical signals, thus exerting its bacteriostatic effect (Kesselmeier et al. 2002). Looking forward to the application prospect of VOCs, it is also possible to control the addition of VOCs produced by $B$. subtilis as a protective gas and to combine the existing technologies, such as changing atmosphere preservation and film closed gas modulation, for efficient preservation. In the early stage, the fermented bean curd was used to isolate a biocontrol fungus, which has good control effect on the postharvest preservation of litchi. The strain was identified as B. subtilis, its number is CF-3, registered and preserved at the China Center for Type Culture Collection, with the deposit number CCTCC M 2016125. In the previous study, we demonstrated that the antibacterial protein and volatile substances produced by the biocontrol bacteria have good antibacterial effects against various plant pathogenic bacteria (Gao et al. 2016). The VOCs produced by B. subtilis CF-3 during fermentation were isolated and identified by headspace SPME-GC-MS (HS-SPME-GC-MS). A single antibacterial activity test was carried out on 74 compounds contained in B. subtilis CF3 showed that 2,4-ditertiary butylphenol produced the highest inhibitory effect on $C$. gloeosporioides (Gao et al. 2017). However, the mechanism by which the volatile substances produced by $B$. subtilis inhibit the growth of C. gloeosporioides is not clear. Therefore, based on the results of previous investigations, this study further explored the mechanism of action of B. subtilis CF-3 VOCs against the anthracnose of litchi. Physical experiments were conducted to explore the mechanism of VOCs-induced defensive reaction in litchi fruits after harvest. Therefore, it provides an effective basis for the production of biological preservatives for effectively controlling C. gloeosporioides and, thus, for updating the biological preservation technology.

\section{Materials and methods \\ Selection of strain \\ Bacillus strain}

Bacillus subtilis CF-3 (registered in the China Center for Type Culture Collection, CCTCC M 2016125) was 
isolated from fermented bean curd and identified by the Laboratory of Food Safety and Quality Control (School of Life Sciences, Shanghai University) (Gao et al. 2016). B. subtilis CF-3 was cultivated for 7 days at $37^{\circ} \mathrm{C}$, using LB solid medium (Gao et al. 2017).

\section{C. gloeosporioides}

Colletotrichum gloeosporioides Penz. (registered in Agricultural Culture Collection of China, ACCC 36351, provided by the Institute of Environment and Plant Protection, Chinese Academy of Tropical Agricultural Sciences) was cultivated for 7 days at $25^{\circ} \mathrm{C}$, using the potato dextrose agar (PDA) solid medium (Gao et al. 2017).

\section{Fruits}

Litchi fruits of the variety "Guangxi rice litchi" were purchased from Shanghai Wholesale Fruit Market. The fruits that were disease-free, had no obvious wounds, had a neat appearance, and had the same maturity and size were chosen. The selected fruits were pruned and immersed in a $0.1 \%$ sodium hypochlorite solution for $1 \mathrm{~min}$, and then rinsed with tap water and air-dried in the fume hood for use.

\section{Preparation of $24-\mathrm{h}$ fermentation broth from B. subtilis CF-3}

Bacillus subtilis CF-3 was cultivated on LB solid medium for $24 \mathrm{~h}$ at $37^{\circ} \mathrm{C}$, gently scraped with an inoculating loop and transferred into $100 \mathrm{~mL}$ LB liquid medium in a conical flask and cultured at $37^{\circ} \mathrm{C}$ in a rotary shaker at $150 \mathrm{r} /$ min for $24 \mathrm{~h}$. Subsequently, the culture solution was diluted to a concentration of approximately $10^{8} \mathrm{cfu} / \mathrm{mL}$, using a hemocytometer, to obtain a seed cultivation solution and carry out a volatile bacteriostatic test.

\section{Effects of VOCs on C. gloeosporioides in litchi fruit}

The disinfected and air-dried litchi fruits were subcutaneously injected at a site $5 \mathrm{~mm}$ deep into the pulp with $20 \mu \mathrm{L}$ of the prepared fungal spore suspension at a point of the equator of the litchi fruits using a 1-mL syringe. The injected litchi fruits were dried in the fume hood until use. Twenty litchis were placed on a plastic tray sterilized with $75 \%$ ethanol (4 rows $\times 3$ rows of grooves), positioning two litchis in each groove and then placing a piece of filter paper in each of the head and tail grooves (90 $\mathrm{mm}$ diameter) in the middle of the tray. Subsequently, $200 \mu \mathrm{L}$ of $1 \mathrm{~mol} / \mathrm{L}$ 2,4-di-tert-butylphenol (diluted with dimethyl sulfoxide) or CF-3 $24 \mathrm{hFB}$ was added to each of the two filter paper sheets. Then, quickly put the tray containing litchi fruits into a cardboard box $(45 \mathrm{~cm} \times 35 \mathrm{~cm} \times 10 \mathrm{~cm})$ and sealed. The box was wrapped in a gas-conditioned bag, and kept at room temperature $\left(25{ }^{\circ} \mathrm{C}\right)$. The samples were taken by unpacking the bag every day starting from $\mathrm{d} 1$ for a total of 4 days, with three replicates in each treatment. Owing to the instability of VOCs, the bags were discarded directly after unpacking and were not re-sealed.

$$
\mathrm{A}(\%)=\frac{\Delta-\delta}{\Delta} \times 100 \%
$$

where $\mathrm{A}$ is the inhibition rate; $\Delta$ is the diameter of the lesion in the blank group; $\delta$ is the diameter of the lesion in the treatment group.

The litchi fruit treatment settings were as follows: (1) blank control group (no treatment); (2) $1 \mathrm{~mol} / \mathrm{L} \mathrm{2,4-di-}$ tert-butylphenol (diluted with dimethyl sulfoxide); (3) CF-3 $24 \mathrm{~h}$ fermentation broth.

\section{Effects of VOCs on C. gloeosporioides spore germination}

Five milliliters of sterile water containing $0.05 \%$ Tween 80 was added to the PDA plate of C. gloeosporioides precultivated for 7 days. The resulting spore suspension was then filtered through eight layers of sterile cheesecloth, and its concentration was adjusted to $1 \times 10^{4}$ conidia/mL using distilled water.

The treatment solution was evenly spread on LB solid medium, and the spore suspension $(20 \mu \mathrm{L})$ was evenly spread on fresh PDA medium. The reagent-coated solid medium was inverted on the PDA coated with spore suspension, and then the plate was sealed with parafilm and incubated at $28{ }^{\circ} \mathrm{C}$. At the same time, the LB solid medium coated with the same volume of distilled water or dimethyl sulfoxide was used as a blank control, and the same volume of thymol solution was applied as a positive control and cultivated under the same conditions. Three parallel replicates were set up for each processing group. The germination of spores was respectively observed by light microscopy at $2,4,6,8,10$, and $12 \mathrm{~h}$, and the length of the germ tube exceeded half of the maximum diameter of spores was considered as the spore germination standard. When the spore germination rate in the blank control group exceeded $90 \%$, the spore germination rates of all treatment groups were measured and calculated using the following formula:

$$
R(\%)=\frac{\mathrm{n}}{t} \times 100 \%
$$

where $\mathrm{R}$ is the spore germination rate; $\mathrm{n}$ is the number of spores that have sprouted; $\mathrm{t}$ is the total number of spores.

The treatment settings were as follows: (1) blank control group (dimethyl sulfoxide, distilled water); (2) positive control group $(500 \mathrm{mg} / \mathrm{L}$ thymol solution with distilled water); (3) $1 \mathrm{~mol} / \mathrm{L}$ 2,4-di-tert-butylphenol (diluted with dimethyl sulfoxide); (4) CF-3 $24 \mathrm{~h}$ fermentation broth. 
Preparation of fumigation treatment $C$. gloeosporioides by $B$. subtilis CF-3 VOCs

The method described by Arrebola et al. (2010) and Jiang et al. (2014) was used to evaluate the inhibitory effects of VOCs produced by B. subtilis CF-3 against C. gloeosporioides. After $24 \mathrm{~h}$ fermentation, $20 \mu \mathrm{L}$ of B. subtilis CF-3 fermentation broth was aspirated, and evenly spread on LB solid medium. Subsequently, a plug $(\varnothing 7 \mathrm{~mm})$ from the fungal agar, which was incubated for 7 days, was punched and placed at the center of a fresh PDA medium. Finally, the LB solid medium was inverted on the fungusattached PDA solid medium and sealed with a parafilm to reduce the loss of VOCs. The sealed petri dish was placed in an electrothermal incubator at $28^{\circ} \mathrm{C}$ for 7 days.

The treatment settings were as follows: (1) blank control group (dimethyl sulfoxide, distilled water); (2) $1 \mathrm{~mol} / \mathrm{L}$ 2,4-di-tert-butylphenol (diluted with dimethyl sulfoxide); (3) CF-3 $24 \mathrm{~h}$ fermentation broth.

\section{Effects of VOCs on the cellular morphology of $C$. gloeosporioides}

Preparation of electron microscope fixative (2.5\% neutral glutaraldehyde): $10 \mathrm{~mL}$ glutaraldehyde solution (25\%), $50 \mathrm{~mL}$ phosphate buffer solution (0.2 M; $0.588 \mathrm{~g}$ $\mathrm{NaH}_{2} \mathrm{PO}_{4} \cdot 2 \mathrm{H}_{2} \mathrm{O}, 5.8 \mathrm{~g} \mathrm{Na}_{2} \mathrm{HPO}_{4} \cdot 12 \mathrm{H}_{2} \mathrm{O}$ were dissolved and mixed in $100 \mathrm{~mL}$ sterile distilled water and the $\mathrm{pH}$ was adjusted to $7.2-7.4$, standby), $40 \mathrm{~mL}$ sterile distilled water were mixed, and a $2.5 \%$ neutral glutaraldehyde solution was prepared.

The scraped hyphae (blank control, single VOC treatment, CF-3 24 h fermentation broth) were soaked in the electron microscope fixative and sent to Shanghai Yuyi Testing Center for electron microscopy.

\section{Effect of VOCs on fatty acid content in C. gloeosporioides cell membrane Cell membrane lipid extraction Soxhlet}

In a round bottom flask, $0.2 \mathrm{~g}$ of the fumigated fungal sample was mixed with $100 \mathrm{~mL}$ of methanol to reflux for $2 \mathrm{~h}$, and the reflux was steamed to $5 \mathrm{~mL}$ with a rotary evaporator.

\section{Fatty acid derivatization}

The extracted lipid concentrate was hydrolyzed with potassium hydroxide-methanol solution (11 g/L) at $90{ }^{\circ} \mathrm{C}$ for $10 \mathrm{~min}$. Total fatty acids were then derivatized with $2 \mathrm{~mL}$ sulfuric acid methanol $(10 \%, \mathrm{~V} / \mathrm{V})$ at $90{ }^{\circ} \mathrm{C}$ for $20 \mathrm{~min}$. After adding $250 \mu \mathrm{L}$ of the internal standard ( $1 \mathrm{~g} / \mathrm{L}$ methyl nonanoate), the fatty acid solution was extracted with $2 \times 6 \mathrm{~mL}$ of isooctane and occasionally oscillated. The water in the isooctane layer was removed with anhydrous sodium sulfate. Finally, it was concentrated by rotary evaporation to $1 \mathrm{~mL}$ and stored at $20{ }^{\circ} \mathrm{C}$ for analysis.

\section{GC-MS analysis}

According to the method described by Tang et al. (2011), a $1 \mu \mathrm{L}$ sample was injected in an HP-5 ms capillary column to analyze the fatty acid content though GC-MS. All samples were analyzed in triplicate, and the standard deviation was calculated.

\section{Effects of VOCs on the content of ergosterol in the $C$. gloeosporioides cell wall} Extraction and derivatization of ergosterol from the cell wall The sample was accurately weighed to $0.2 \mathrm{~g}$ and placed in a $40-\mathrm{mL}$ covered vial. Subsequently, $20 \mathrm{~mL} \mathrm{NaOH}$ solution $(5 \mathrm{~g} \mathrm{NaOH}+5 \mathrm{~mL}$ sterile distilled water $+95 \mathrm{~mL}$ methanol) and $20 \mu \mathrm{L}$ of $1 \mathrm{mg} / \mathrm{mL}$ internal standard stock solution [100 mg accurately weighed 7-dehydrocholesterol standard $\left(\mathrm{VD}_{3}\right)$ was accurated to $0.1 \mathrm{mg}$ and dissolved in methanol and diluted to $100 \mathrm{~mL}$ to obtain $1 \mathrm{mg} / \mathrm{mL}$ internal standard stock solution]. The stock solution was hydrolyzed at $80{ }^{\circ} \mathrm{C}$ for $2 \mathrm{~h}$ and then cooled to room temperature $\left(25^{\circ} \mathrm{C}\right)$. Five milliliters of the above hydrolyzate was taken in a $15-\mathrm{mL}$ stoppered tube $3 \mathrm{~mL}$ of $n$-hexane was added, followed by vortexing for $2 \mathrm{~min}$. After standing, $1 \mathrm{~mL}$ of the supernatant was taken into a chromatography bottle, and the solvent was dried in a $40{ }^{\circ} \mathrm{C}$ water bath, followed by the addition of $300 \mu \mathrm{L} \mathrm{N}, O$ bis(trimethylsilyl)trifuoroacetamide (BSTFA) to derivatize ergosterol at $80{ }^{\circ} \mathrm{C}$ for $45 \mathrm{~min}$. After cooling, the ergosterol sample was analyzed by GC-MS.

\section{GC-MS analysis}

According to the method of Saraf et al. (1997), Pasanen et al. (1999), Sha et al. (2008), and Liu et al. (2007), selection monitoring (SIM), target ion ( $\mathrm{M} / \mathrm{Z})$ : ergosterol 363, and internal standard 351 were used to detect the content of ergosterol. All samples were analyzed in triplicate, and the standard deviation was calculated.

Preparation of ergosterol standard solution and preparation of standard curve were referred to Yuan et al. (2007). The standard series of ergosterol solutions were determined and analyzed by GC-MS under the same conditions. A regression analysis was used to obtain the integrated peak areas of ergosterol and internal standard.

\section{Effects of CF-3 VOCs on related enzyme activities and indicators in litchi fruits}

The methods of selection and pretreatment of litchi varieties were the same as the methods of bacteriostasis determination. The litchi fruit treatment settings were as follows: (1) blank control group (no treatment); (2) 
$1 \mathrm{~mol} / \mathrm{L}$ 2,4-di-tert-butylphenol (diluted with dimethyl sulfoxide); (3) CF-3 $24 \mathrm{~h}$ fermentation broth.

\section{Litchi fruit sampling}

Ten litchis were taken from a box as a parallel. Thus, a total of 30 different litchis were taken from three boxes. The peel and the nucleus of the sampled litchis were removed and their pulps were torn into small pieces, which were frozen in liquid nitrogen and stored in a refrigerator at $-80^{\circ} \mathrm{C}$ for later use.

\section{Measurement of polygalacturonase and cellulose}

To extract polygalacturonase (PG) and cellulose, $10.0 \mathrm{~g}$ of litchi fruit sample was ground in $95 \%$ ethanol in an ice bath and centrifuged at $4{ }^{\circ} \mathrm{C}$ and $12,000 \times g$ for $20 \mathrm{~min}$. The above step was repeated with $80 \%$ ethanol. The extraction buffer solution was added to the precipitate. After centrifugation, the supernatant was collected and stored at $4{ }^{\circ} \mathrm{C}$.

The PG (or cellulose) extract $(0.5 \mathrm{~mL})$ was mixed with the reaction solution, and incubated at $37^{\circ} \mathrm{C}$ for $1 \mathrm{~h}$. Subsequently, $1.5 \mathrm{~mL} 3,5$-dinitrosalicylic acid reagent was immediately added dropwise, heated in a boiling water bath for $5 \mathrm{~min}$, diluted to $25 \mathrm{~mL}$, and shaken. The absorbance was determined at $540 \mathrm{~nm}$. The enzyme extract boiled for 5 min was used in the blank control group.

\section{Measurement of antioxidant system and phenylalanine ammonia-lyase}

To extract peroxidase (POD), polyphenol oxidase (PPO), catalase (CAT), superoxide dismutase (SOD), superoxide anion $\left(\mathrm{O}_{2}^{-}\right)$, hydrogen peroxide $\left(\mathrm{H}_{2} \mathrm{O}_{2}\right)$, malondialdehyde (MDA), and phenylalanine ammonia-lyase (PAL), $5.0 \mathrm{~g}$ of litchi fruit samples were ground in the extraction buffer solution in an ice bath and centrifuged at $4{ }^{\circ} \mathrm{C}$ and $12,000 \times g$ for $30 \mathrm{~min}$ (20 min for $\mathrm{O}_{2}{ }^{-}, \mathrm{H}_{2} \mathrm{O}_{2}$, and MDA). The supernatants were used as enzyme extracts.

The determination methods of POD, PPO, CAT, SOD, $\mathrm{H}_{2} \mathrm{O}_{2}, \mathrm{O}^{2-}$ and PAL were referred to Wang et al. (2013). The absorbance was determined at $470 \mathrm{~nm}$ for POD, $420 \mathrm{~nm}$ for PPO, $560 \mathrm{~nm}$ for SOD, $530 \mathrm{~nm}$ for $\mathrm{O}^{2-}$, $412 \mathrm{~nm}$ for $\mathrm{H}_{2} \mathrm{O}_{2}, 290 \mathrm{~nm}$ for PAL and $240 \mathrm{~nm}$ for CAT, taking distilled water as a reference. The content of MDA was determined by thiobarbituric acid colorimetry. The absorbance was measured at 450, 532, and $600 \mathrm{~nm}$. In the blank control group, the supernatant was replaced with $2.0 \mathrm{~mL}$ of tricarboxylic acid (TCA).

\section{Measurement of superoxide anion, chitinase, and $\beta$-1,3-glucanase}

The production rate of superoxide anion and the activities of chitinase $(\mathrm{CHI})$ and $\beta$-1,3-glucanase (GLU) were measured using commercial kits (Comin Biotechnology, Co., Ltd, Suzhou, CHN).

\section{Statistical analysis}

The SPSS 18.0 software (SPSS Inc., Chicago, IL, USA) was used to conduct the statistical analysis. Duncan's post hoc test was applied to compare the mean values. A significance level of $P<0.05$ was used to determine the significant differences. Mean values with standard deviations were reported. Additionally, MS Excel 2013 (Microsoft Corp., Redmond, WA, USA) was used to calculate and draw standard curves, and Origin Pro 9 (OriginLab Corp., Northampton, MA, USA) was used to create charts.

\section{Result}

\section{Effects of VOCs on C. gloeosporioides in vivo and in vitro}

As shown in Fig. 1A, the brown lesions appear around the injection site on $\mathrm{d} 3$. The inhibition rate of the 2,4-ditert-butylphenol treatment group was significantly higher than the blank group $(P<0.05)$. On $d 4$, the inhibition rates of the 2,4-di-tert-butylphenol and CF-3 VOCs treatment groups were significantly higher than the blank group $(P<0.05)$, indicating that the 2,4-di-tert-butylphenol and
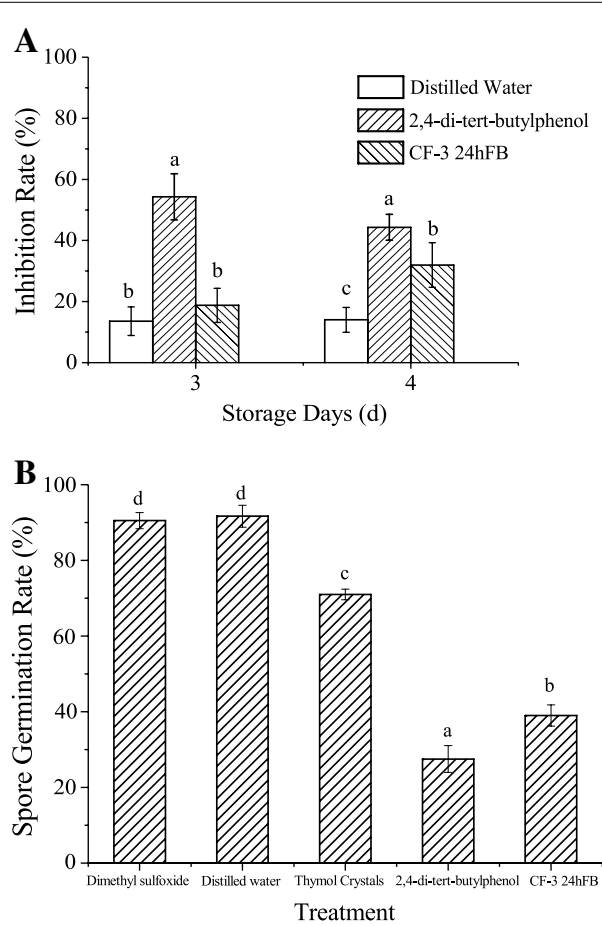

Fig. 1 Inhibitory effect of different treatments on C. gloeosporioides (A) and spores' germination (B) of C. gloeosporioides. Each column represents the mean value from three independent experiments, and vertical bars represent the standard errors of the means for each treatment. Different letters represent significant differences $(P<0.05)$ 
CF-3 VOCs can effectively inhibit the growth and development of C. gloeosporioides in litchi fruits.

In the spore germination test, the spores in the VOC treatment groups, as well as in the distilled water and dimethyl sulfoxide groups (blank control groups), germinated after $6 \mathrm{~h}$; therefore, the spore germination rates of all groups were measured at $6 \mathrm{~h}$ (Fig. 1B). It could be seen from the figure that 2,4-di-tert-butylphenol and CF-3 $24 \mathrm{hFB}$ could greatly inhibit the germination of C. gloeosporioides spores. The germination rates of the spores treated with 2,4-di-tert-butylphenol and 24hFB were
$27.50 \pm 3.53 \%$ and $39.23 \pm 2.83 \%$, respectively, indicating that the two reagent treatments could greatly inhibit the germination of C. gloeosporioides spores, thus playing an effective role in disease prevention.

\section{Effects of VOCs on the mycelial morphology of $C$. gloeosporioides}

The effect of B. subtilis CF-3 VOCs on the mycelial morphology of C. gloeosporioides is showed in Fig. 2. The scanning electron microscopy showed that the hyphae in the blank group were intact and their surface was smooth

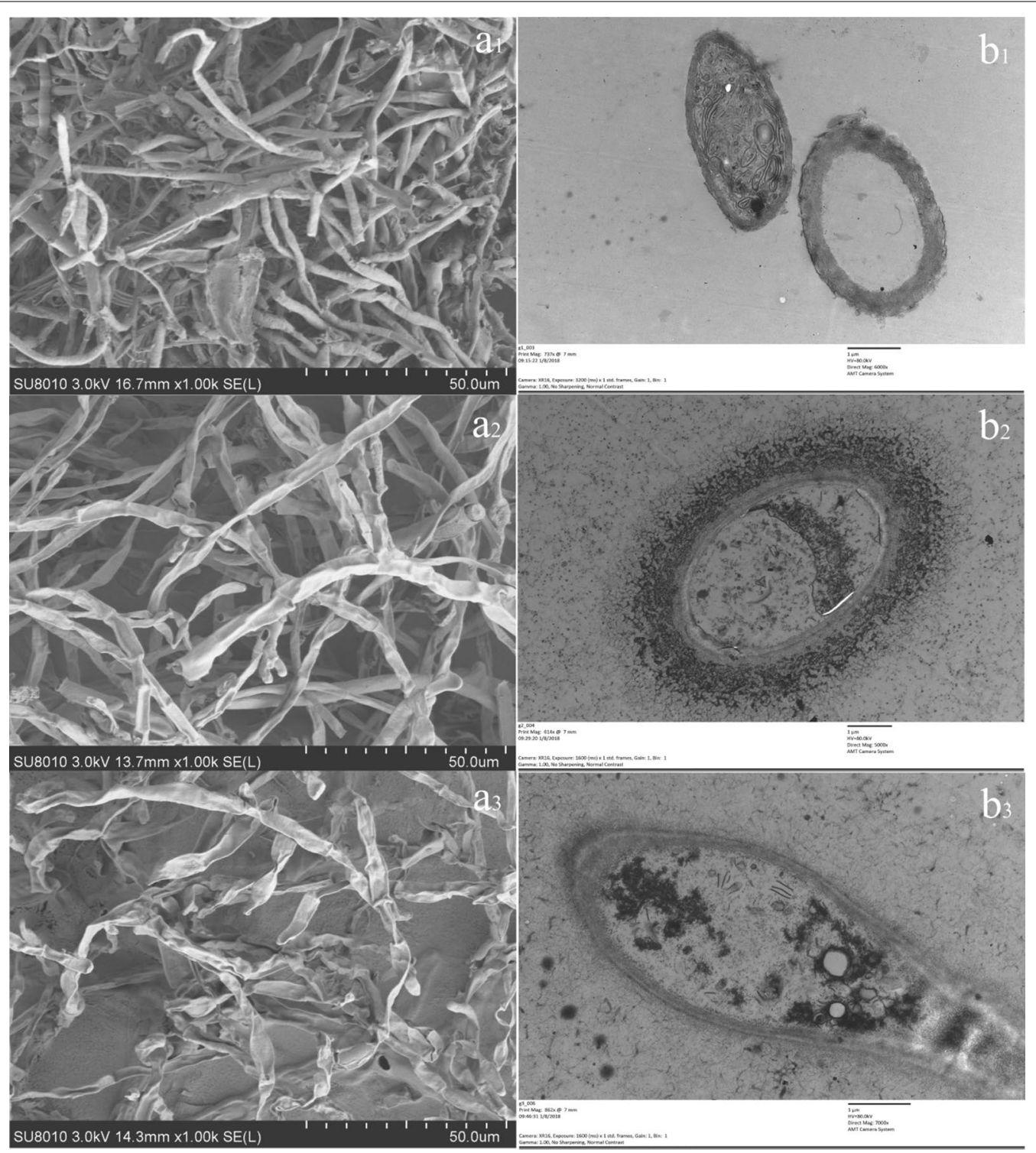

Fig. 2 Electron microscope detection of C. gloeosporioides. The images on the left side of the figure show scanning electron micrographs of $C$. gloeosporioides and the images on the right side show transmission electron micrographs. a1 and b1 are the images from the blank control group, $\mathbf{a} \mathbf{2}$ and $\mathbf{b} \mathbf{2}$ are images from the 2,4-di-tert-butylphenol treatment, $\mathbf{a} \mathbf{3}$ and $\mathbf{b} \mathbf{3}$ are the images from the CF-3 24hFB treatments 
and plump $\left(\mathrm{a}_{1}\right)$; after treatment with 2,4-di-tert-butylphenol, the hyphae shrunk and ruptured $\left(\mathrm{a}_{2}\right)$; after treatment with CF-3 24hFB, the hyphae shrunk and twisted, leading to a sinuous or wrinkled surface $\left(\mathrm{a}_{3}\right)$. The transmission electron microscopy showed that the hyphae of the blank group exhibited a typical fungal ultrastructure $\left(b_{1}\right)$; after treatment with 2,4-di-tert-butylphenol, the protoplast membrane was broken, and the cell wall was separated, and the intracellular components were severely destroyed, forming a shell $\left(\mathrm{b}_{2}\right)$; after treatment with CF-3 24hFB, the cell organelles began to shrink $\left(b_{3}\right)$. These results showed that the VOCs fumigation treatment can cause the hyphae of $C$. gloeosporioides to shrink and rupture, cell organelles to shrink and form vacuoles, and cell wall to break, thereby inhibiting the growth of $C$. gloeosporioides.

\section{Effect of VOCs on fatty acid content in C. gloeosporioides cell membrane}

The results of the GC-MS analysis showed that the blank control group contains more long-chain unsaturated fatty acids and a small amount of saturated fatty acids. The relative content of cis-linoleic acid decreased and that of trans-linoleic acid, oleic acid, palmitic acid, and stearic acid increased after 2,4 di-tert-butylphenol and CF-3 $24 \mathrm{hFB}$ treatment (Table 1), indicating that the fatty acid unsaturation in the cell membrane decreased and the membrane fluidity weakened, resulting in the leakage of contents.

\section{Effects of VOCs on the content of ergosterol in the $C$. gloeosporioides cell wall}

In this test, the standard curve of ergosterol was $y=20.563 x+0.3462$, with a correlation coefficient of 0.9995 (Table 2), which showed a good correlation. In the blank control group, the content of ergosterol in the cell wall treated with 2,4-di-tert-butylphenol and CF-3 24hFB was significantly reduced $(P<0.05)$. This showed that the treatment with VOCs reduced the content of ergosterol in the cell wall of C. gloeosporioides and affected the integrity of the fungal cell wall, thus weakening the cell membrane flow and material transport, affecting the viability of fungal cells.

\section{Effects of CF-3 VOCs on related enzyme activities and activity indexes \\ Pathogenic enzymes}

As shown in Fig. 3, the polygalacturonase activity in litchi fruits of the three groups increased with increasing storage days, but the increasing rate and enzyme activity of the blank group were much higher than that of the two treatment groups, indicating that 2,4-di-tert-butylphenol

Table 1 Fatty acid content of cell wall of C. gloeosporioides

\begin{tabular}{|c|c|c|c|}
\hline \multirow[t]{2}{*}{ Fatty acid } & \multicolumn{3}{|l|}{ Treatment } \\
\hline & No treatment & 2,4-Di-tert-butylphenol & CF-3 24h FB \\
\hline Palmitic acid C16:0 (\%) & $22.16 \pm 3.28 b$ & $21.24 \pm 3.09 b$ & $27.87 \pm 1.57 \mathrm{a}$ \\
\hline Stearic acid C18:0 (\%) & $0 \mathrm{c}$ & $8.17 \pm 1.84 b$ & $16.93 \pm 2.51 \mathrm{a}$ \\
\hline 9-Hexadecenoic acid C16:1 (\%) & $0 \mathrm{c}$ & $1.23 \pm 0.27 \mathrm{a}$ & $0.53 \pm 0.08 b$ \\
\hline 16-Heptadecenoic acid C17:1 (\%) & $14.22 \pm 1.52 \mathrm{a}$ & $0 b$ & $0 \mathrm{~b}$ \\
\hline Oleic acid C18:1 (\%) & $0 \mathrm{c}$ & $36.97 \pm 4.21 \mathrm{a}$ & $28.63 \pm 2.48 b$ \\
\hline Trans 9-octadecenoic acid C18:1 (\%) & $\mathrm{OC}$ & $1.19 \pm 0.18 \mathrm{a}$ & $0.62 \pm 0.07 b$ \\
\hline Linoleic acid C18:2 (\%) & $29.67 \pm 3.03 \mathrm{a}$ & $0 \mathrm{c}$ & $3.41 \pm 0.95 b$ \\
\hline Trans-linoleic acid C18:2 (\%) & $20.90 \pm 1.67 b$ & $31.20 \pm 2.94 \mathrm{a}$ & $22.01 \pm 1.23 b$ \\
\hline 8,11,14-Docosic acid C22:3 (\%) & $13.05 \pm 2.16 \mathrm{a}$ & $0 \mathrm{~b}$ & $0 \mathrm{~b}$ \\
\hline Unsaturated/saturated & $3.51 \pm 0.24 \mathrm{a}$ & $2.40 \pm 0.29 b$ & $1.23 \pm 0.15 c$ \\
\hline
\end{tabular}

The mean and standard error in the table were taken from three replicates, and the different letters indicated that the different treatments of the same strain had significant differences $(P<0.05)$

Table 2 Content of ergosterol in C. gloeosporioides

\begin{tabular}{llcc}
\hline & Treatment & Peak area ratio & Ergosterol content (mg/g) \\
\hline Electron microscope & No treatment & $5.9118 \pm 0.1523$ & $3.2479 \pm 0.0889 \mathrm{a}$ \\
& 2,4-Di-tert-butylphenol & $3.4303 \pm 0.1689$ & $1.7998 \pm 0.0986 \mathrm{~b}$ \\
& CF-3 24 hFB & $3.0325 \pm 0.1153$ & $1.5677 \pm 0.0673 \mathrm{~b}$ \\
\hline
\end{tabular}

The mean and standard error in the table were taken from three replicates, and the different letters indicated that the different treatments of the same strain had significant differences $(P<0.05)$ 

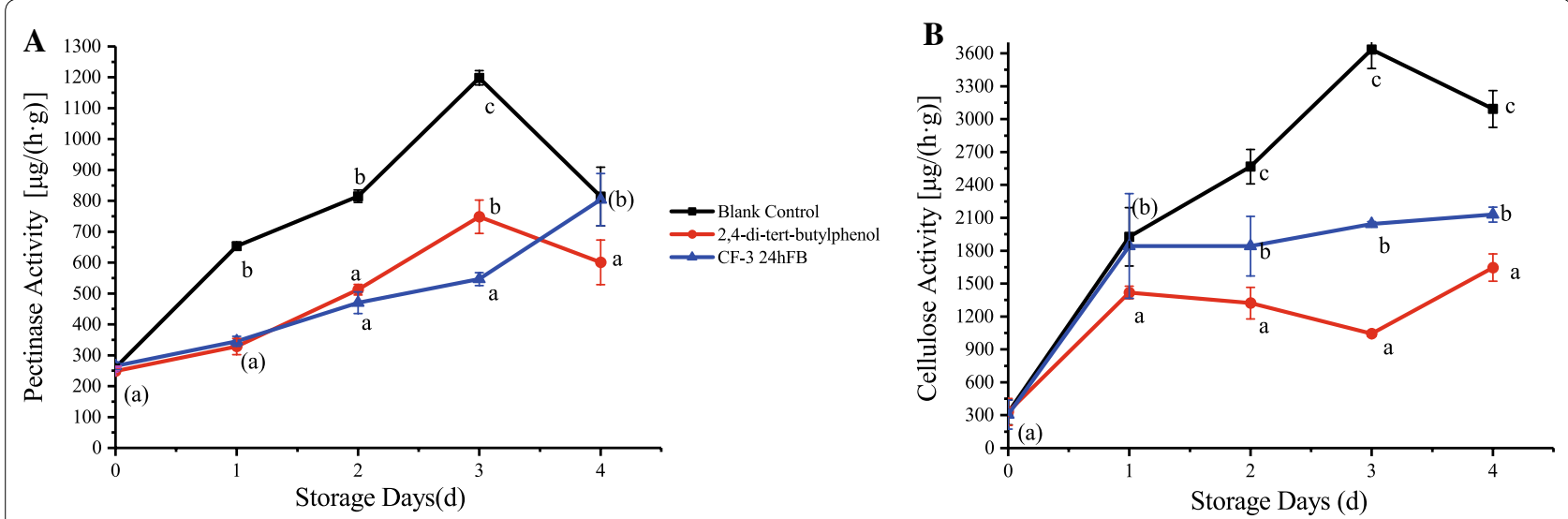

Fig. 3 Influence of different treatments on pectinase (A) and cellulase (B) activity in vivo during storage. The mean and standard error in the figure were taken from three replicates, and different letters indicate that different treatments on the same storage days were significantly different $(P<0.05)$
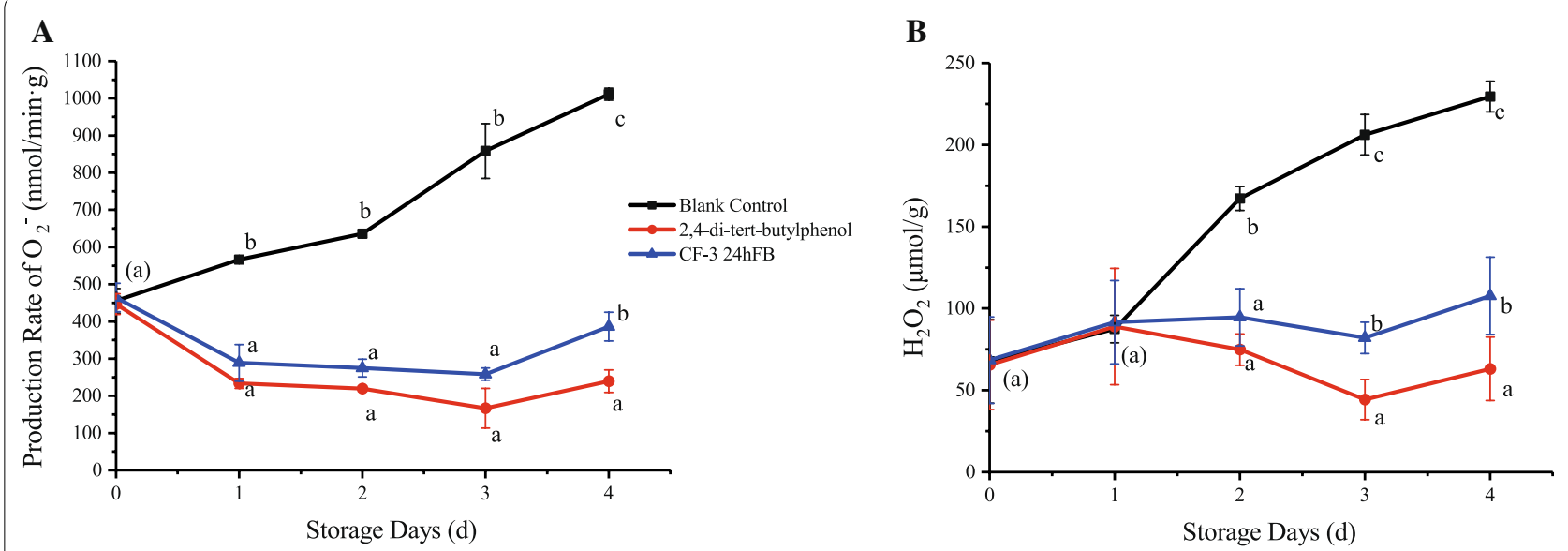

Fig. 4 Influence of different treatments on the production rate of superoxide anion (A) and the amount of hydrogen peroxide (B) produced in vivo during storage. The mean and standard errors in the figure were taken from three replicates, and different letters indicate that different treatments in the same storage days were significantly different $(P<0.05)$

and CF-3 24hFB can inhibit the increase in the activity of polygalacturonase. The cellulose activity in the blank group showed a significant upward trend with the increase in the number of storage days (Fig. 3B), while the activity of the two treatment groups leveled off after d2. The two treatment groups showed a slight increase on $\mathrm{d} 4$, but the enzyme activity was significantly lower than that of the blank group, indicating that 2,4-di-tertbutylphenol and CF-3 24hFB treatment can significantly inhibit the increase in cellulose activity.

\section{Active oxygen}

The production rate of superoxide anion and hydrogen peroxide content during the storage of litchi fruits are shown in Fig. 4. During the whole storage process, the production rate of superoxide anion in the two treatment groups showed a significantly decreasing trend in contrast to the blank group. The production rate of the superoxide anion in the 2,4-di-tert-butylphenol treatment group decreased continuously until $\mathrm{d} 3$, and increased slightly on $\mathrm{d} 4$, but was lower than the other groups, indicating that 2,4-di-tert-butylphenol can induce oxidation resistance, thereby inhibiting the production rate of superoxide anion in litchi fruit. For hydrogen peroxide, the content in the treatment groups decreased significantly after 2 days, and the content on d3 reached its lowest level. In general, the hydrogen peroxide content in the 2,4-di-tert-butylphenol treatment group was significantly lower than the other two groups. 


\section{Degree of cell damage}

The changes in MDA content and cell membrane permeability during storage are shown in Fig. 5. During the whole storage process, the MDA content in the litchi fruits of the two treatment groups increased with the storage time, but the inhibiting effects of the 2,4-ditert-butylphenol and CF-3 24hFB treatments were significantly better than the control treatment. During the storage process, the cell membrane permeability increased continuously, indicating that the fruit cells became more and more severe with the increase of storage days. Generally, the MDA content and cell membrane permeability in the treatment groups were the lowest, indicating that the 2,4-di-tert-butylphenol and CF-3 $24 \mathrm{hFB}$ treatments can effectively prevent cell membrane lipid peroxidation.

\section{Antioxidant enzymes}

The activities of four antioxidant enzymes (PPO, POD, CAT, and SOD) showed first an increasing trend and then a decreasing trend during storage (Fig. 6). Except PPO, the activities of the three enzymes were significantly higher in the two treatment groups than in the blank control group, while the PPO activities were slightly higher in the treatment groups than in the blank group, indicating that both treatments can induce the production of antioxidant enzymes in the fruit to remove excess hydrogen peroxide and free radicals from the fruit. The activities in the 2,4-di-tert-butylphenol treatment group were higher than those in the CF-3 24hFB treatment group, and both reached the peak on $\mathrm{d} 3$, indicating that 2,4-di-tert-butylphenol can effectively induce fruit oxidation resistance to prevent oxidative damage. This result corresponds to the result of the lowest MDA content and cell membrane permeability in the 2,4-di-tert-butylphenol treatment group.

\section{Disease-resistant enzymes}

The activities of the three enzymes related to plant disease resistance (PAL, CHI, and $\beta-1,3-\mathrm{GLU}$ ) showed an increasing trend followed by a decreasing trend during storage (Fig. 7), and the enzyme activities in the two treatment groups were all higher than the blank control group, indicating that both treatments can induce fruit disease resistance. The enzyme activities in the 2,4-ditert-butylphenol treatment group were significantly higher than those in the CF-3 24hFB treatment group, and both reached the peak on $\mathrm{d} 3$, indicating that 2,4-ditert-butylphenol can effectively induce plant disease resistance and resist fungal attack.

\section{Discussion}

In general, the effect of 2,4-di-tert-butylphenol is better than that of CF-3 24hFB. 2,4-di-tert-butylphenol is one of the components isolated from CF-3 $24 \mathrm{hFB}$ by headspace SPME-GC-MS (HS-SPME-GC-MS) in our previous experiments. The results of earlier bacteriostatic experiments showed that many compounds in CF-3 24hFB had no bacteriostatic effect, while 2,4-di-tert-butylphenol had the best bacteriostatic effect on C. gloeosporioides. Mi-Ae et al. (2006) found that 2,4-di-tert-butylphenol has good antioxidant activity and has many great effects in scavenging free radicals. Sang and Kim (2012) also isolated 2,4-di-tert-butylphenol from VOCs produced by bacterial strain (GSE09) antagonistic to Phytophthora capsici on pepper and proved to be bacteriostatic, which was the same as our previous bacteriostatic results. Therefore, 2,4-di-tert-butylphenol was selected as the positive
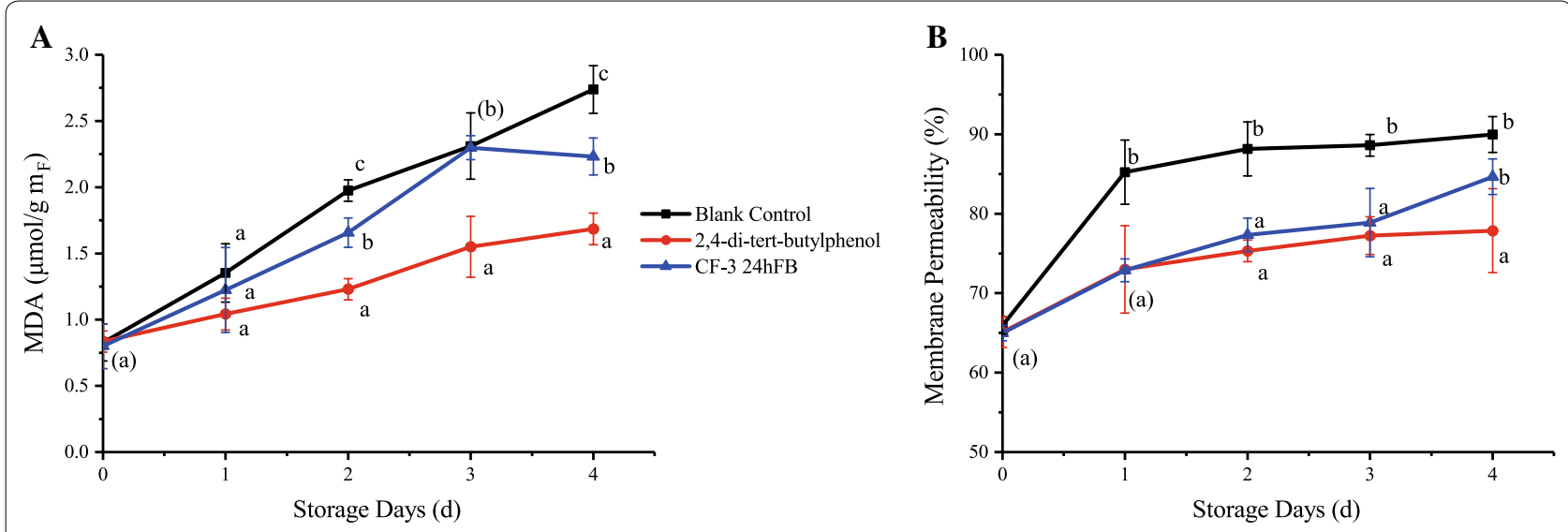

Fig. 5 Influence of different treatments on the amount of MDA (A) and membrane permeability (B) in vivo during storage. The mean and standard errors in the figure were taken from three replicates, and different letters indicate that different treatments in the same storage days were significantly different $(P<0.05)$ (MDA malondialdehyde) 

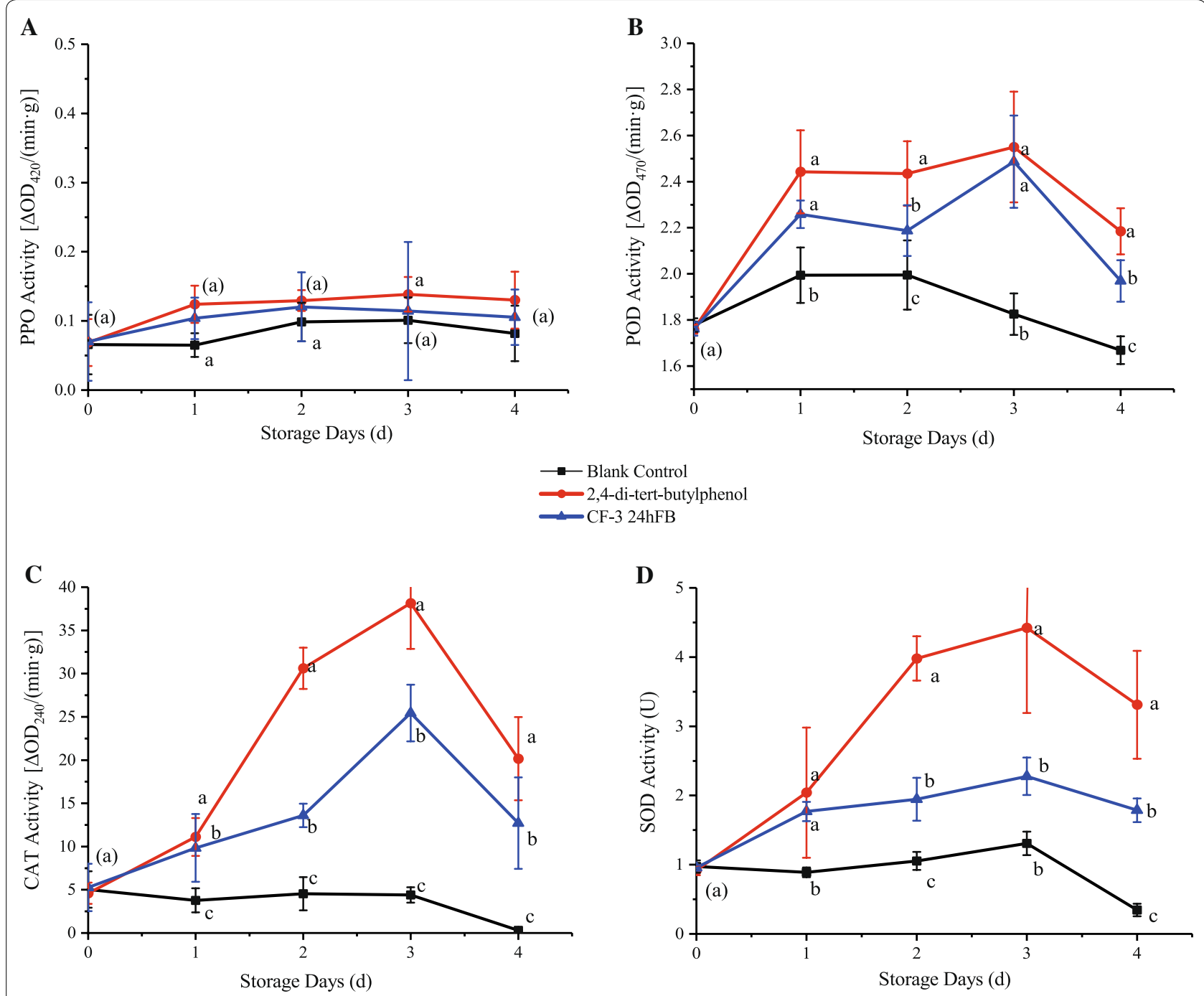

Fig. 6 Influence of different treatments on POD (A), PPO (B), CAT (C) and SOD (D) activity in vivo during storage. The mean and standard errors in the figure were taken from three replicates, and different letters indicate that different treatments in the same storage days were significantly different $(P<0.05)$ (POD peroxidase, PPO polyphenol oxidase, CAT catalase, SOD superoxide dismutase)

control to compare the antibacterial effect horizontally. In this experiment, CF-3 24hFB had a significant inhibitory effect on C. gloeosporioides, and the antibacterial effect of the 2,4-di-tert-butylphenol treatment group was better than that of the CF-3 $24 \mathrm{hFB}$ treatment group.

The cell wall and membrane not only maintain the shape of the cell, increasing the mechanical strength of the cell, but also control a part of the physical and information transport while bearing the swell pressure generated by the protoplasts, and provides certain disease resistance. The scanning and transmission electron microscopies showed that after fumigating with 2,4 di-tert-butylphenol and CF-3 24hFB, the hyphae were shrunk, twisted, and broken, resulting in a striated or wrinkled surface. In addition, the intracellular components were seriously damaged, the organelles began to shrink, the plasmalemma ruptured, and the cell wall contents completely leaked, forming an empty shell. It can be seen that 2,4 di-tert-butylphenol and VOCs in CF-3 $24 \mathrm{hFB}$ can act on the cell wall and cell membrane system of fungi, destroying their basic functions.

The lipid composition of the fungal cell membrane and its contents are also an important parameter of the cell membrane. Lipids have many important functions, including increasing cell membrane stability, regulating cell membrane fluidity, and reducing the permeability of water-soluble substances (Heaton and Randall 2011). Regarding the relationship between the content of 

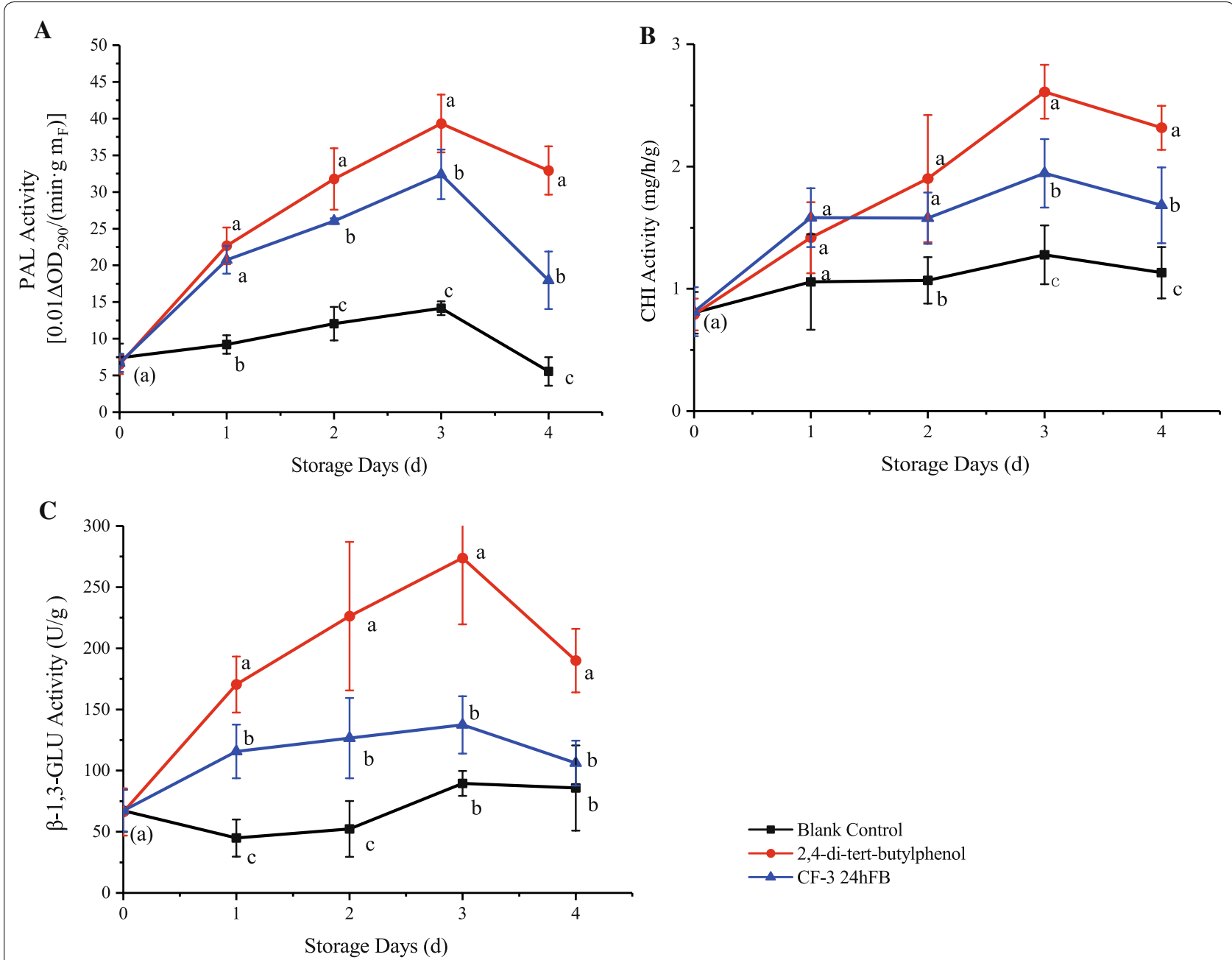

Fig. 7 Influence of different treatments on PAL (A), CHI (B) and $\beta-1,3-G L U(\mathbf{C})$ activity in vivo during storage. The mean and standard errors in the figure were taken from three replicates, and different letters indicate that different treatments performed on the same storage days were significantly different $(P<0.05)$ (PAL phenylalanine ammonia lyase, $C H I$ chitinase, $\beta-1,3-G L U \beta-1,3$-glucanase)

unsaturated fatty acids in fungi and cell membrane integrity, Cronan (2015) found that if the cell membrane lacked unsaturated fatty acids, it would cause loss of content and dissolution. Bayer et al. (2000) found that if the saturated fatty acid content in the cell membrane was at high, it would lead to an increase in cell membrane stiffness and a decrease in membrane fluidity, which might easily cause cell rupture. In this experiment, the degree of unsaturation of VOC-treated fungal cells decreased to varying extents, likely reflecting a VOC-mediated decrease in fungal cell membrane fluidity, which led to cell rupture and leakage of contents.

In addition, ergosterol is present in various fungi, and it is a major component of the cell wall of filamentous fungi. It plays an essential role in the growth and function of cells. In addition to controlling the fluidity, asymmetry, and integrity of cell membranes, ergosterol is helpful for the normal activities of enzymes in cell wall. Pinto et al. (2011) reported that 1,2-dihydroxy xanthone had high antibacterial activity as well as reduced the ergosterol contents of Trichophyton mentagrophytes, Aspergillus fumigatus, Candida albicans, and Cryptococcus neoformans. This was consistent with the bacteriostatic effect of B. subtilis CF-3 VOCs observed in this study. In this experiment, the content of ergosterol in the cell walls of the VOC-treated fungus decreased to varying extents, which could reflect that VOCs destroyed the fungal cell wall and interfered with the normal function of the cell membrane.

Pectinase and cellulase are cell wall degrading enzymes produced by pathogenic bacteria, which are one of the factors causing fruit disease (Amadioha 2010). 2,4-di-tert-butylphenol and VOCs can inhibit the activity of the two pathogenic enzymes, thereby 
protecting the pectin and cellulose components of the litchi fruits from the two pathogenic enzymes.

Superoxide anion and hydrogen peroxide will be produced in the fruit body. Excessive superoxide anion and hydrogen peroxide can induce the peroxidation of unsaturated fatty acids in membrane lipids, produce lipid free radicals, and further induce the peroxidation of membrane lipids, leading to increased membrane permeability and cell damage or death (Macarisin et al. 2010). MDA is one of the main products of membrane lipid peroxidation, and its content can be used as an indicator of lipid peroxidation, reflecting the degree of membrane lipid peroxidation. At the same time, when the cell membrane of the fruit and vegetable tissues is damaged, electrolyte extravasation in the cell membrane will increase the electrical conductivity, which can reflect the degree of injury to the fruit and vegetable (Liang 2008). 2,4-di-tert-butylphenol and VOCs can inhibit the production rate of superoxide anion in litchi fruit, prevent the occurrence of membrane lipid peroxidation and remove excess hydrogen peroxide from the fruit.

POD, PPO, CAT and SOD are four typical antioxidant enzymes in fruits. The enzyme activity of these four enzymes can reflect the ability of the plant to remove excess oxygen free radicals and its antioxidant capacity (Zheng et al. 2007). PAL, CHI and $\beta-1,3-$ GLU are typical disease-resistant enzymes in fruits. These three enzymes are closely related to the resistance to stress and disease of plants, and play an important role in the normal growth and development of plants and the resistance to pathogen invasion (Fortunato et al. 2015). 2,4-di-tert-butylphenol and VOCs can induce the production of antioxidant enzymes and disease-resistant enzymes in the fruit, effectively induce plant disease resistance and resist fungal attack.

In this study, the physical and flat-panel experiments show that VOCs produced by B. subtilis CF-3 can prevent the decay of litchi fruits infected by $C$. gloeosporioides and can significantly inhibit the spore germination and growth of pathogenic bacteria. Meanwhile, it was further proved that VOCs can destroy the structure of fungal cells and induce post-harvest disease resistance in litchi fruits.

\section{Authors' contributions}

$H G, R Z, P L$ and $P Z$ designed the experiments. PL, PZ and $M Z$ performed the experiments. PL, MZ, SW and PZ analyzed the data. $H G, R Z, M Z, P L$, and SW drafted the manuscript. All authors read and approved the final manuscript.

\section{Funding and acknowledgments}

This research was supported by the project of Science and Technology Innovation Action Plan of Shanghai Science and Technology Commission of China (No. 18391901300).

\section{Availability of data and materials}

The data supporting the conclusions of this article are included within the article. Data and materials can also be requested from the corresponding author.

\section{Ethics approval and consent to participate}

This article does not contain any studies with human participants or animals performed by any of the authors.

\section{Consent for publication}

Not applicable.

\section{Competing interests}

The authors declare that the research was conducted in the absence of any commercial or financial relationships that could be construed as a potential competing interests.

Received: 6 July 2019 Accepted: 15 July 2019

Published online: 27 July 2019

\section{References}

Ahimou F, Deleu MJP (1999) Surfactin and iturin A effects on Bacillus subtilis surface hydrophobicity. Enzyme Microb Technol 27:749-754

Ahmad Z, Wu J, Chen L, Dong W (2017) Isolated Bacillus subtilis strain 330-2 and its antagonistic genes identified by the removing PCR. Sci Rep 7:1777

Amadioha AC (2010) Depolymerisation of potato tissue by oxalic acid, polygalacturonase and cellulase produced by Aspergillus niger (Short Communication)xs. Mol Nutr Food Res 38:341-342

Ambrico A, Trupo M (2017) Efficacy of cell free supernatant from Bacillus subtilis ET-1, an Iturin A producer strain, on biocontrol of green and gray mold. Postharvest Biol Technol 134:5-10

Arrebola E, Sivakumar D, Korsten L (2010) Effect of volatile compounds produced by Bacillus strains on postharvest decay in citrus. Biol Control 53:122-128

Bayer AS, Prasad R, Chandra J, Koul A, Smriti M, Varma A, Skurray RA, Firth N, Brown MH, Koo SP (2000) In vitro resistance of Staphylococcus aureus to thrombin-induced platelet microbicidal protein is associated with alterations in cytoplasmic membrane fluidity. Infect Immun 68:3548-3553

Cronan JE (2015) Bacterial membrane lipids: where do we stand? Annu Rev Microbiol 57:203-224

Fortunato AA, Debona D, Bernardeli AMA (2015) Defence-related enzymes in soybean resistance to target spot. J Phytopathol 163:731-742

Gao H, Xu X, Dai Y, He H (2016) Isolation, identification and characterization of Bacillus subtilis CF-3, a bacterium from fermented bean curd for controlling postharvest diseases of peach fruit. Food Sci Technol Res 22:377-385

Gao H, Xu X, Zeng Q, Li P (2017) Optimization of headspace solid-phase microextraction for GC-MS analysis of volatile compounds produced by biocontrol strain Bacillus subtilis CF-3 using response surface methodology. Food Sci Technol Res 23:583-593

Heaton NS, Randall G (2011) Multifaceted roles for lipids in viral infection. Trends Microbiol 19:368-375

Jiang C, Shi J, Liu Y, Zhu C (2014) Inhibition of Aspergillus carbonarius and fungal contamination in table grapes using Bacillus subtilis. Food Control 35:41-48

Kesselmeier J, Ciccioli P, Kuhn U, Stefani P, Biesenthal T, Rottenberger S, Wolf A, Vitullo M, Valentini R, Nobre A (2002) Volatile organic compound emissions in relation to plant carbon fixation and the terrestrial carbon budget. Glob Biogeochem Cycles 16:73

Leelasuphakul W, Hemmanee P, Chuenchitt S (2008) Growth inhibitory properties of Bacillus subtilis strains and their metabolites against the green mold pathogen (Penicillium digitatum Sacc.) of citrus fruit. Postharvest Biol Technol 48:113-121

Li XY, Mao ZC, Wu YX, Ho HH, He YQ (2015) Comprehensive volatile organic compounds profiling of Bacillus species with biocontrol properties by head space solid phase microextraction with gas chromatography-mass spectrometry. Biocontrol Sci Technol 25:132-143

Liang J (2008) Effects of infection with Botryosphaeria dothidea on cell membrane permeability, soluble sugar and MDA content in Poplar Calli. Scientia Silvae Sinicae 44:72-77 
Liu AY (2006) Developments of anthracnose on harvested litchi fruits and the effects of the disease on storage of the fruits. Acta Phytophylacica Sinica 33:351-356

Liu WH, Ding B, Ruan XM, Xu HT, Yang J, Liu SM (2007) Analysis of free and conjugated phytosterols in tobacco by an improved method using gas chromatography-flame ionization detection. J Chromatogr A 1163:304-311

Macarisin D, Droby S, Bauchan G, Wisniewski M (2010) Superoxide anion and hydrogen peroxide in the yeast antagonist-fruit interaction: a new role for reactive oxygen species in postharvest biocontrol? Postharvest Biol Technol 58:194-202

Mi-Ae Y, Tae-Sook J, Doo-Sang P, Ming-Zhe X, Hyun-Woo O, Kyoung-Bin S, Woo Song L, Ho-Yong P (2006) Antioxidant effects of quinoline alkaloids and 2,4-di-tert-butylphenol isolated from Scolopendra subspinipes. Biol Pharm Bull 29:735-739

Nicholson WL, Munakata N, Horneck G, Melosh HJ, Setlow P (2000) Resistance of Bacillus endospores to extreme terrestrial and extraterrestrial environments. Microbiol Mol Biol Rev 64:548

Pasanen AL, Ylipietilä K, Pasanen P, Kalliokoski P, Tarhanen J (1999) Ergosterol content in various fungal species and biocontaminated building materials. Appl Environ Microbiol 65:138

Pinto E, Afonso C, Duarte S, Vale-Silva L, Costa E, Sousa E, Pinto M (2011) Antifungal activity of xanthones: evaluation of their effect on ergosterol biosynthesis by high-performance liquid chromatography. Chem Biol Drug Des 77:212-222

Qi NL, Li T, Zhou HL, Yang CL (2015) Survey of sulfur dioxide residues in litchi preservation process in hainan province. Appl Mech Mater 713-715:2920-2923

Sang MK, Kim KD (2012) The volatile-producing Flavobacterium johnsoniae strain GSE09 shows biocontrol activity against Phytophthora capsici in pepper. J Appl Microbiol 113:383-398

Saraf A, Larsson L, Burge H, Milton D (1997) Quantification of ergosterol and 3-hydroxy fatty acids in settled house dust by gas chromatography-mass spectrometry: comparison with fungal culture and determination of endotoxin by a Limulus amebocyte lysate assay. Appl Environ Microbiol $63: 2554$
Setlow P (2010) Spores of Bacillus subtilis: their resistance to and killing by radiation, heat and chemicals. J Appl Microbiol 101:514-525

Sha Y, Deng C, Liu B (2008) Development of C18-functionalized magnetic silica nanoparticles as sample preparation technique for the determination of ergosterol in cigarettes by microwave-assisted derivatization and gas chromatography/mass spectrometry. J Chromatogr A 1198:27-33

Sonenshein AL, Losick R (1994) The gram-positive world. (Book reviews: Bacillus subtilis and other gram-positive bacteria. biochemistry, physiology, and molecular genetics). Science 263:546-548

Tang Y, Li YY, Li HM (2011) Comparison of lipid content and fatty acid composition between tuber fermentation mycelia and natural fruiting bodies. J Agric Food Chem 59:4736

Vespermann A, Kai M, Piechulla AB (2007) Rhizobacterial volatiles affect the growth of fungi and Arabidopsis thaliana. Appl Environ Microbiol 73:5639-5641

Waewthongrak W, Pisuchpen S, Leelasuphakul W (2015) Effect of Bacillus subtilis and chitosan applications on green mold (Penicilium digitatum Sacc.) decay in citrus fruit. Postharvest Biol Technol 99:44-49

Wang JD, Zhu XR, Sun GC (2001) Application of post-harvest litchi disease with opponent bacteria. China Fruits 6:42-44

Wang LJ, Qi-Yun MU, Wen-Xiang LI, Wang SK, Zhang SJ (2013) Effect of microvacuum conditions on broccoli chlorophyll degradation and endogenous oxidation resistance. Food Sci 34:312-317

Yuan JP, Wang JH, Liu X, Kuang HC, Zhao SY (2007) Simultaneous determination of free ergosterol and ergosteryl esters in Cordyceps sinensis by HPLC. Food Chem 105:1755-1759

Zheng X, Tian S, Meng X, Li B (2007) Physiological and biochemical responses in peach fruit to oxalic acid treatment during storage at room temperature. Food Chem 104:156-162

\section{Publisher's Note}

Springer Nature remains neutral with regard to jurisdictional claims in published maps and institutional affiliations.

\section{Submit your manuscript to a SpringerOpen ${ }^{\circ}$ journal and benefit from:}

- Convenient online submission

- Rigorous peer review

- Open access: articles freely available online

- High visibility within the field

- Retaining the copyright to your article

Submit your next manuscript at springeropen.com 